\title{
DESIGUALDADES E INTERSECCIONALIDADES: DESLINDANDO A COMPLEXA TRAMA DAS HIERARQUIAS E AGENCIAMENTOS
}

\author{
Silvana Aparecida Mariano (UEL) ${ }^{1}$ \\ Márcia dos Santos Macêdo (UFBA)²
}

desafio de compreensão das dinâmicas (re)produtoras de
desigualdades é um tema sempre atual nas Ciências Sociais e anima uma ampla gama de pesquisas. Nos diferentes campos teóricos que buscam iluminar essa agenda de investigações, amplia-se o reconhecimento de que o uso de análises interseccionais tem, cada vez mais, possibilitado contribuições dotadas de um elevado valor heurístico. Uma das razões para a recente construção desse consenso em torno da noção de interseccionalidades deve-se ao reconhecimento de que, diante da complexidade dos processos de produção das desigualdades sociais e das identidades políticas, é preciso enxergar não apenas a interconexão das lógicas produtoras das diversas formas de opressão e privilégio, mas também a potencialidade de visibilização dos movimentos de resistência, reconhecendo os processos de agência e autonomização dos sujeitos.

O presente dossiê materializa a proposta de realizar uma reunião de estudos teóricos e empíricos a respeito das diferentes

\footnotetext{
1 Docente do Departamento e do Programa de Pós-Graduação em Ciências Sociais da Universidade Estadual de Londrina, Brasil. E-mail: silvanamariano@yahoo.com.br

2 Docente do Departamento de Estudos de Gênero e Feminismo e do Programa de PósGraduação em Estudos Interdisciplinares sobre Mulheres, Gênero e Feminismo - PPG-NEIM da Universidade Federal da Bahia, Brasil. E-mail: msmacedo@ufba.br
} 
dimensões das desigualdades que privilegiem a compreensão da complexa dinâmica das relações sociais, ou seja, das várias intersecções de marcadores sociais como gênero/sexo, idade/geração, raça/etnia, sexualidade/orientação sexual e classe, através das quais são atualizados conjuntos de relações de diferenciação/articulação na nossa sociedade.

Na construção deste dossiê, queremos evidenciar o nexo entre o campo dos estudos sobre as desigualdades e o campo dos estudos interseccionais. A concepção das desigualdades desde uma perspectiva multidimensional, tal como as contribuições de Amartya Sen (1993, 2004, 2008) e Martha Nussbaum $(2002,2003)$ com a abordagem das capacidades e dos funcionamentos, possibilita uma conexão produtiva e consistente com as análises das interseccionalidades, a exemplo das teorizações de Kimberlé Crenshaw (1991, 2002) e Avtar Brah (2006), entre tantas outras referências, internacionais e nacionais, mobilizadas pelas autoras e autores do presente dossiê. Também contribui para a produção desses estudos as teorizações de descentramento dos sujeitos. Se rejeitamos as explicações que supõem o sujeito como uma unidade centrada, estável, coerente e fixa, e, ao mesmo tempo, adotamos, por exemplo, a perspectiva da situação, do contexto ou da contingência (BUTLER, 1998, 2003; LACLAU; MOUFFE, 2006; MARIANO, 2005), a multidimensionalidade e a interseccionalidade tornam-se recursos teóricos e metodológicos necessários para a produção das análises. O fortalecimento da agenda dos direitos humanos como campo articulador de diferentes sujeitos, é, ainda, outro fator histórico que contribuiu para a emergência e consolidação dos estudos aqui destacados. Esses diferentes campos teóricos, provenientes de tradições teóricas distintas, cruzando-se com vários outros campos e com os temas como estrutura e agência, identidade e desigualdades, formam um escopo promissor tanto para a ação política quanto para 
a explicação científica sobre as desigualdades e o agenciamento dos atores/atrizes sociais.

A resposta à chamada de Mediações para este dossiê não poderia ter sido mais positiva: foram mais de cinquenta trabalhos inéditos, escritos por pesquisadoras e pesquisadores de diferentes regiões do país, produzindo uma miríade de temáticas a partir de um amplo leque de campos disciplinares e também interdisciplinares - o que tornou, simultaneamente, árduo e prazeroso o processo de seleção dos textos para apreciação pelo grupo de pareceristas ad hoc. Nossos sinceros e respeitosos agradecimentos a todas as pessoas que enviaram suas contribuições para este número e àquelas que generosamente trabalharam para sua qualificação e finalização.

Como se pode captar a partir do conjunto de contribuições que compõem este dossiê, a abordagem das desigualdades que prioriza o foco na renda e nas classes sociais precisa ser revista para abarcar várias outras dimensões produtoras e reprodutoras das desigualdades. E, no que se refere às interseccionalidades, vale destacar desde o início que não se trata de reiterar o lugar comum que tomou conta de muitos discursos que supõem uma operação matemática de somatória entre as diferentes dimensões. A metáfora segundo a qual se adicionam desvantagens sociais aos sujeitos à medida em que se agregam novas dimensões ou variáveis, como, por exemplo, classe, gênero, raça e orientação sexual, não é consistente com a perspectiva interseccional. De acordo com a lógica da somatória, as mulheres estão em situação de desvantagem social em virtude de seu gênero; se ela, além de ser mulher, for pobre, há intensificação de sua vulnerabilidade; se, além de mulher e pobre for também negra, maior é sua vulnerabilidade; se for mulher, pobre, negra e lésbica, há, ainda, maior vulnerabilidade; e assim se segue a lógica de adicionar fatores e intensificar o grau de vulnerabilidade. Essa lógica supõe que as dinâmicas constitutivas do processo de (re)construção das identidades, do agenciamento 
dos atores e da configuração das desigualdades são lineares e determinadas. De acordo com a perspectiva das interseccionalidades, diferentemente, os marcadores sociais da diferença e as variadas dimensões das desigualdades operam em contextos determinados, apresentam variadas possibilidades de combinações e, diante dessas combinações, diferentes fatores são mutuamente potencializados, reorganizados, (re)significados e hierarquizados.

A emergência das preocupações quantoàs interseccionalidades pode ser localizada sobretudo na produção de movimentos sociais e de estudos acadêmicos do Norte. Contudo, como evidencia este dossiê, na atualidade tais preocupações têm influências, e, inclusive têm sido renovadas, a partir de estudos e interesses desenvolvidos nos países periféricos, no chamado Sul Global, e são também expressivas na produção brasileira.

Osestudosorientadospelaperspectivadasinterseccionalidades tendem a enfatizar as articulações entre diferentes atores/atrizes sociais ou movimentos sociais. É relevante, todavia, registrar também que persistem conflitos e por vezes até contradições entre esses atores/ atrizes e movimentos. No cenário brasileiro, por exemplo, o caso da Lei Maria da Penha é ilustrativo a esse respeito. Nesse contexto, a mudança na legislação agenciada e defendida pelos movimentos feministas, moveu-se na direção do Estado penal, enquanto os movimentos negros, por seu turno, mostram-se empenhados na crítica ao Estado penal, dado que esse Estado atinge predominantemente a população negra e pobre no Brasil. Por outro lado, há um leque de proposições legislativas em tramitação na Câmara dos Deputados e no Senado brasileiros cujos conteúdos expressam evidentemente a redução de direitos de populações já desempoderadas na sociedade brasileira. Essa conjuntura, por sua vez, põe em evidência as intersecções políticas entre, por exemplo, classe, gênero, sexualidade e religiosidade e têm levado ao reforço dos embricamentos entre as lutas dos movimentos 
de mulheres, de trabalhadores, negros, LGBT e outros, contribuindo assim para as articulações entre esses movimentos.

Este dossiê traz uma ênfase no "desempoderamento" dos sujeitos produzido a partir das interseccionalidades. Esse viés não ignora o fato de que as interseccionalidades são também produtoras de identidades, de agência e de formas de empoderamento. No entanto, do ponto de vista da preocupação com a mudança social, no sentido de redução das desigualdades, justifica-se o perfil do presente dossiê. Além do mais, a julgar pelo conteúdo das dezenas de artigos que foram submetidos ao dossiê, podemos inferir que essa linha de abordagem é atualmente bastante difundida entre as pesquisas brasileiras.

Assim, este dossiê nos permitiu concretizar uma proposta temática que buscou abarcar pesquisas que tratam, nos planos teórico e/ ou empírico, dos constrangimentos impostos pelo entrelace de lógicas produtoras de desigualdades, mas também dos agenciamentos, do desenvolvimento das capacidades e de autonomia, das possibilidades e das limitações para o empoderamento de sujeitos subordinados, das interações entre estrutura social e atores em contextos específicos, dos efeitos de políticas públicas para a redução das desigualdades e ampliação dos processos de empoderamento individual e coletivo. Com essa vasta intencionalidade, o dossiê está constituído por dois blocos de produções: o primeiro, de natureza mais teórica, versa sobre a trajetória de construção do conceito de interseccionalidades, os debates (e embates!) nos campos teórico e da intervenção, bem como alguns limites e possibilidades em torno desta "lente de análise social"; o segundo bloco é composto por textos baseados em pesquisas empíricas e tratam, a partir de uma perspectiva interseccional, de temáticas como empoderamento e trabalho doméstico, mulheres e participação política, sociabilidades virtuais nas classes populares, juventude e contravenção, desigualdade na política formal e mulheres em profissões estigmatizadas (garis). 
No primeiro texto, os cientistas políticos Flavia Birolli e Luis Felipe Miguel abrem o dossiê com o artigo "Gênero, raça e classe: opressões cruzadas e convergências na reprodução das desigualdades", realizando um resgate de importantes estudos feministas que tratam das convergências entre gênero, classe e raça e sua circunscrição no debate teórico das últimas décadas - destacando as interlocuções com as teorias feministas marxistas ou socialistas, o feminismo negro e os estudos das interseccionalidades. A partir de uma análise cuidadosa da produção de um conjunto de autores/as que se debruçam sobre o entrelaçamento de relações de opressão, exploração e dominação, o texto nos convida a compreender a riqueza e complexidade ensejadas por tais análises - notadamente heterogêneas e alimentadas por diferentes matizes teóricos e pela complexa relação com uma diversidade de sujeitos políticos.

Antes de tratar mais especificamente do conceito de interseccionalidades, os autores realizam um esforço de contextualização dos entrelaces de gênero, raça e classe na sociedade brasileira, a partir da apresentação e análise de dados de pesquisas em torno de questões como pobreza, chefia familiar, mercado de trabalho, maternidade e direitos reprodutivos. Asssim, através da compreensão da multiplicidade de opressões nas frentes discutidas no artigo, os autores sinalizam para a impossibilidade do entendimento das desigualdades a partir da leitura isolada de qualquer uma das variáveis em questão, argumentando que as hierarquias sociais, ao operarem conjuntamente, nos desafiam a buscar formas igualmente complexas de explicação e transformação sociais.

Nessa mesma direção, o artigo da antropóloga Cecilia Sardenberg, intitulado "Caleidoscópios de gênero: gênero e interseccionalidades na dinâmica das relações sociais", busca, igualmente, produzir uma proposta consistente de teorização que não se permite dissociar o exercício de análise teórica de objetivos 
de emancipação social. A autora toma como foco a reflexão sobre a importância dos determinantes de gênero para a compreensão da dinâmica das relações sociais, mas nos alerta para a sua vinculação a uma perspectiva feminista de compreensão da realidade e, mais que isso, a um pensamento feminista que enxerga nosso entorno igualmente atravessado por outras matrizes de opressão para além do sexismo, como o capitalismo, o racismo, o etarismo e a lesbo/homofobia - isso porque "estão imbricadas ou em 'simbiose', constituindo-se como matrizes de opressão que se entrelaçam e se reforçam, forjando sistemas de estratificação e opressão interseccionados" (SARDENBERG, 2015, p. 56).

Em seu texto, Sardenberg opta pelo resgate de parte importante do processo de teorização dos feminismos, por considerá-lo o terreno fértil que favoreceu a produção de uma perspectiva de análise interseccional das relações sociais. Para realizar essa tarefa, revisita o "debate sobre sexo e classe" realizado entre feministas marxistas e socialistas e feministas radicais, bem como traz a luz importantes contribuições das interpelações às teorias feministas produzidas pelos diferentes feminismos - o que significa retomar o debate provocado pelas feministas negras, as produções voltadas para a questão geracional ou ainda aquelas produzidas a partir de inspiração das teorias queer. Através do debate teórico apresentado, a autora nos sinaliza para impossibilidade da afirmação de uma categoria sobredeterminante teoricamente consistente e politicamente estável - seja, por exemplo, para situar a opressão da categoria "mulheres", a exploração da "classe trabalhadora" ou ainda o racismo que atinge agrupamentos caracterizados como "negros" -, e ressalta a necessidade de se pensar as condições históricas específicas produtoras de desigualdades através de matrizes macroestruturais de opressão e a complexidade das relações de simultaneidade entre essas desigualdades. 
Nosso terceiro texto, "Interseccionalidade e pensamento feminista: as contribuições históricas e os debates contemporâneos acerca do entrelaçamento de marcadores sociais da diferença", de autoria do também antropólogo Carlos Eduardo Henning, realiza uma ampla e consistente revisão do debate teórico nacional e internacional em torno da noção de interseccionalidades entre as diversas abordagens do pensamento feminista, dos estudos sobre mulheres e das teorias de gênero contemporâneas. $\mathrm{O}$ autor, após reconstituir importantes momentos de formação do debate interseccional nos Estados Unidos e no Reino Unido, realiza um mapeamento das principais vertentes no campo da análise interseccional, mostrando que um dos traços mais marcantes desse campo é a sua polifonia - o que significa também dizer que se trata de um campo de questionamentos e disputas. Nessa direção, o texto pontua as principais críticas dirigidas às abordagens de maior destaque no campo das análises interseccionais, mapeando convergências e divergências nas reflexões de um significativo número de produções a esse respeito no Brasil e, principalmente, fora dele.

Em resposta ao conjunto de críticas direcionadas ao conceito de interseccionalidades, Henning propõe uma formulação de interseccionalidade que valoriza, simultaneamente, a força das estruturas produtoras de desigualdades sociais - decorrentes do entrelace de uma pluralidade de marcadores além de classe, gênero e raça! - e a atenção ao desenvolvimento de táticas de agenciamento, destacando a necessidade de se compreender as distintas formas de agência interseccional. Em suas próprias palavras: "a interseccionalidade, portanto, precisa ser concebida também a partir de práticas sociais decorrentes da interação conjuntural desses marcadores não apenas em seus efeitos de produção de desigualdades" (HENNING, 2015, p. 117). Na dinâmica produzida pelo diálogo crítico-propositivo sobre os limites e potencialidades do conceito, o texto alerta para a necessidade de ampliação do seu 
escopo empírico, "descolando" as reflexões desse campo de estudos na ênfase em torno de determinados "objetos priviliegiados" (como é o caso das "mulheres subalternizadas"); rassalta ainda a urgência de uma profunda transformação dos fluxos globais na geopolítica de produção e consumo do conhecimento e, com isso, assume a defesa de uma ruptura com a "colonização epistemológica do pensamento" produzida nos "Centros" (EUA e alguns países europeus) e uma valorização das "teorizações interseccionais descentradas".

Em seguida, abrindo o bloco de artigos produzidos a partir de pesquisas empíricas, temos o artigo "Conectadas: experiência de subalternidade ajuda-mútua feminina online entre mulheres de classes populares", de autoria conjunta dos cientistas sociais Lara Facioli e Richard Miskolci. O texto, produzido a partir de pesquisa etnográfica em plataformas e aplicativos de acesso a redes sociais e de entrevistas, focaliza, através da intersecção das diferenças de classe e gênero, a ressignificação da experiência de subalternidade experenciada por mulheres das classes populares moradoras da Baixada Fluminense e região pauperizada da Zona Oeste do Rio de Janeiro e que, por meio do relacionamento via a utilização de mídias digitais, constroem novas formas de sociabilidade e subjetivação.

Os autores buscam uma aproximação das experiências e vivências dos sujeitos da pesquisa, focalizando as articulações dos determinantes de classe e gênero; mais especificamente, se voltam para o entendimento da forma como as transformações econômicas e sociais recentes têm se refletido no cotidiano das mulheres das classes populares e nas chances de concretização de seus projetos de mobilidade social. A utilização de perspectiva de análise interseccionais representou a possibilidade de compreender " [...] uma tensão fundante entre a ampliação dos horizontes aspiracionais e as ainda escassas ferramentas que permitiriam, por outro lado, trilhar caminhos seguros de ascensão" (FACIOLI; MISKOLCI, 2015, p. 148). 
Nesse encontro entre projetos e oportunidades, a pesquisa aponta para a ampliação dos processos de individualização, de consumo e de possibilidades de intensificação, via as novas sociabilidades virtuais, de uma maior seletividade nas escolhas afetivas e de projetos de vida, fortalecendo o "processo reflexivo em torno dos horizontes aspiracionais" desses sujeitos.

No texto "A dinâmica de desigualdades e interseccionalidades no trabalho de mulheres da limpeza pública urbana: o caso das garis", as sociólogas Lourdes Maria Bandeira e Tânia Mara Campos de Almeida apresentam os resultados de uma pesquisa em curso sobre uma categoria profissional do Distrito Federal - mulheres garis - cuja configuração em termos de interconexão de importantes marcadores sociais - tais como gênero, raça e classe - representa uma situação prototípica de desigualdades interseccionais. As autoras apresentam o escopo da pesquisa e uma breve etnografia do grupo de trabalhadoras entrevistadas, deixando entrever como as discriminações sofridas por esta categoria profissional são produto da perversa articulação entre sexismo, racismo e desigualdades de classe, agravadas por um conjunto de características históricas da formação da sociedade brasileira - fortemente marcada por um passado escravista e por uma modalidade de cidadania restrita, direcionada a reduzida parcela da população, notadamente benéfica, portanto, aos grupos mais próximos do padrão masculino, branco, europeu, heterossexual e de classe dominante.

A questão da desigualdade interseccional que atinge a categoria profissional estudada, ganha, com a exposição das autoras, uma materialidade desconcertante, pois, evidencia de maneira irrefutável - no trabalho extenuante, na saúde negligenciada, no pouco acesso a políticas públicas, na violência física e simbólica, no baixo nível de remuneração, na invisibilidade do grupo, entre outros - a articulação 
perversa de discriminações que se realiza no que as autoras chamam de "interjogos de desigualdades e abjeção".

Tal como as garis, a categoria trabalhadoras domésticas traz ainda bastante viva a herança do passado escravista, constituindo-se na pior ocupação no mercado de trabalho formal do país - mesmo com todas as lutas travadas historicamente e após as recentes conquistas da categoria com a aprovação da "PEC das domésticas". $\mathrm{O}$ artigo da antropóloga Renata Guedes Mourão Macedo, intitulado "Trabalho doméstico, consumo e interseccionalidade: possibilidades de agência na trajetória de uma (ex)empregada doméstica", discute como "[...] o emprego doméstico no Brasil, sendo uma profissão historicamente feminina, racializada, e que recruta profissionais de classes trabalhadoras, torna-se um lugar estratégico para se pensar na articulação de diferentes marcadores sociais da diferença" (MACEDO, 2015, p. 187). A partir de pesquisa de caráter antropológico e, em especial, através da realização de entrevistas em profundidade com trabalhadoras domésticas em atividade na cidade de São Paulo, a autora elege, como estratégia analítica e expositiva, a apresentação de um estudo de caso, através do qual reconstroi a trajetória de uma trabalhadora doméstica e o esforço desta para colocar em movimento seu projeto de "melhoria de vida".

O texto contextualiza as transformações na economia do país na última década e a ampliação da renda e do consumo de parcela das classes populares habitantes dos grandes centros urbanos, sinalizando para a construção de projetos de mobilidade social a partir da combinação de esforços de investimento simultâneo em trabalho e escolarização. É neste cenário que a autora nos apresenta a potencialidade da noção de intersecionalidades como uma formulação que ressalta a produção e reprodução de múltiplas desigualdades em interseção "sem perder de vista as possibilidades de agência em tais contextos". Para materializar essa tese, a autora nos faz acompanhar o 
curso de vida recente de uma ex-empregada doméstica, apresentando sua narrativa em torno da articulação de estratégias visando ampliar suas possibilidades de agência, mesmo em um contexto marcado por múltiplas desigualdades.

Partindo de um diálogo crítico com as teorias deliberativas, Marie-Hélène Sa Vilas Boas, no artigo "Deliberating on intersectionality: women's conferences in Recife", demonstra como a perspectiva interseccional também é promissora para a análise das desigualdades políticas. O artigo é baseado em estudo das Conferências de Políticas para as mulheres em Recife-PE e tem como objetivo tratar de como a "combinação entre a política do reconhecimento e a deliberação leva tanto à integração quanto à marginalização de algumas mulheres, dependendo dos recursos que elas têm para defender suas 'perspectivas'"' (SA VILAS BOAS, 2015, p. 208). Com base nos dados sobre as demandas formuladas pelas mulheres nas diferentes instâncias dessas conferências de políticas para as mulheres, realizadas em Recife, uma referência para a militância feminista brasileira, a autora analisa como a interseccionalidade se expressa nessas demandas, assim como dá forma às hierarquias entre ativistas feministas e mulheres das organizações comunitárias, com diferentes graus de influência na deliberação, conformando legitimidades desiguais no campo do ativismo das mulheres, de modo que algumas identidades tornam-se mais legítimas que outras, a depender da posse dos capitais acadêmicos e econômicos que pesam para a capacidade de realizar articulações políticas.

De acordo com os dados levantados por Sa Vilas Boas, na etapa municipal das conferências, as articulações mais adotadas na formulação das demandas das mulheres são gênero e raça ou gênero e orientação sexual. A noção de comunidade, invocada pelas mulheres de classes populares e mais frequente nas primeiras etapas das conferências, organizadas em territórios menores, tende 
a perder importância na etapa municipal. Como resultado, a autora destaca as ambivalências decorrentes da combinação entre política de reconhecimento - associada ao projeto de inclusão de diferentes atrizes sociais - e a deliberação - incapaz de neutralizar as desigualdades de influência na tomada de decisão.

Em "Desigualdades da Política no Brasil: representação descritiva na eleição de 2014 para a Câmara de Deputados", o cientista político Augusto N. C. de Oliveira, a partir dos dados do Censo de 2010 e dos números obtidos no processo eleitoral para a Câmara dos Deputados em 2014, realiza uma leitura interseccional dos resultados obtidos que coloca em xeque o nosso modelo de representação e a efetividade da democracia do parlamento brasileiro, afirmando, portanto, que o modelo de participação adotado não impede que alguns grupos se façam representar mais fortemente que outros. O cruzamento de variáveis elementares como sexo, cor, nível de escolarização, ocupação e renda revela uma estrutura profundamente desigual no acesso ao poder político e mostra que a Câmara dos Deputados - que deveria representar nosso povo em toda a sua diversidade de grupos e interesses sociais - está ainda muito longe de ser "um espelho da sociedade brasileira".

O texto apresenta números bastante elucidativos em relação ao processo de afunilamento existente entre o contingente de pessoas nas categorias populacionais recortadas por variáveis como sexo ou cor, por exemplo, e o percentual de candidaturas exitosas de pessoas oriundas desses grupos, ou mais explicitamente: a significativa desproporcionalidade na correlação entre o número total de pessoas que são mulheres ou negros/as e que, respectivamente, se tornam candidatas e são, ao final do processo, efetivamente eleitas. Trata-se de um texto que, em contraste com o conjunto dos artigos do dossiê, não se propõe a desenvolver teorizações em torno das conexões entre desigualdades e intereseccionalidades; por outro lado, podemos 
considerá-lo como um instigante exemplo das potencialidades das análises interseccionais, mostrando como a estrutura das desigualdades sociais de nosso país é transmitida para a política representativa no Brasil.

No artigo intitulado "Jovens, percursos e atividades arriscadas nas corridas ilegais de carros: o risco como componente identitário", de autoria da antropóloga Leila Jeolás e do sociológo Luiz Antonio de Castro Santos, somos convidadas/os a refletir como as interseccionalidades entre geração, classe e gênero iluminam a compreensão dos percursos juvenis, em um contexto social específico de produção de risco, por meio do qual identidades são construídas - os "rachas" com carros e motos - em experiências observadas por meio do método etnográfico, na cidade de Londrina. A apreensão das experiências desses jovens, marcadas pelo risco, violência e discriminação, não podem ser compreendidas pelo uso isolado de uma só categoria analítica. As múltiplas condições juvenis, atravessadas por posicionalidades sociais demarcadas pela referência de masculinidade hegemônica e pelo pertencimento de classe social, expressam "algumas questões sobre formas de enfrentar/suportar/ganhar a vida, nas quais lazer e trabalho, legalidade e ilegalidade, formalidade e informalidade se embaralham de maneira fluida e diferenciada" (JEOLÁS; SANTOS, 2015, p. 266).

Ao recorrer às intersecções entre geração, classe e gênero para a compreensão sobre o risco entre jovens, este estudo destaca a preocupação de "contribuir para o debate no âmbito das ciências sociais sobre os limites entre a potencialidade de agencimento dos atores e as coerções das estruturas sociais" (JEOLÁS; SANTOS, 2015, p. 267). Esta preocupação exemplifica uma forma de atenção à crítica quanto à alta fragmentação das análises interseccionais, o que, segundo os críticos, poderia atingir, no limite, o nível da atomização do indivíduo. Este risco lança um desafio para a análise das ciências sociais: apreender as 
vicissitudes dos diferentes contextos, interseccionados por diferentes critérios de posicionalidade dos indivíduos ou grupos de indivíduos e, ao mesmo tempo, produzir explicações que tenham validade ao menos de médio alcance para o conjunto da sociedade. De acordo com o estudo empírico em questão, o risco, conceito sociológico tomado como central pela sociologia reflexiva (BECK; GIDDENS; LASH, 1997), "se constitui como um componente identitário no percurso de vida dos 'rachadores"'.

Por fim, esperamos que os textos do dossiê contribuam para incentivar debates e produções que reforcem, como apontamos anteriormente, onexoentre ocampo dos estudos sobre as desigualdades e o campo dos estudos interseccionais, favorecendo, assim, a ampliação da produção brasileira nesta perspectiva.

\section{REFERÊNCIAS}

BECK, Ulrich; GIDDENS, Anthony; LASH, Scott. Modernização reflexiva: política, tradição e estética na ordem social moderna. São Paulo: Ed. UNESP, 1997.

BRAH, Avtar. Diferença, diversidade e diferenciação. Cadernos Pagu, Campinas, n. 26, p. 329-376, jan./jun. 2006.

BUTLER, Judith. Fundamentos contingentes: o feminismo e a questão do "pósmodernismo". Cadernos Pagu, Campinas, n. 11, p. 11-42, 1998.

BUTLER, Judith. Problemas de gênero: feminismo e subversão da identidade. Rio de Janeiro: Civilização Brasileira, 2003.

CRENSHAW, Kimberle. Documento para o encontro de especialistas em aspectos da discriminação racial relativo ao gênero. Revista Estudos Feministas, Florianópolis, v. 10, n. 1, p. 171-188, 2002.

CRENSHAW, Kimberle. Mapping the margins: intersectionality, identity politics, and violence against women of color. Stanford Law Review, Stanford, v. 43, p. 1241-1299, 1991.

FACIOLI, Lara; MISKOLCI, Richard. Conectadas: experiências de subalternidade e ajudamútua feminina online entre mulheres de classes populares. Mediações vol. 20 n. 2 (Jul./ Dez. 2015) - Londrina, 2015, p. 129-159. 
HENNING, Carlos Eduardo. Interseccionalidade e pensamento feminista: as contribuições históricas e os debates contemporâneos acerca do entrelaçamento de marcadores sociais da diferença. Mediações vol. 20 n. 2 (Jul./Dez. 2015) - Londrina, 2015, p. 97-128.

JEOLÁS, Leila; SANTOS, Luiz Antonio de Castro. Jovens, percursos e atividades arriscadas nas corridas ilegais de carros: o risco como componente identitário. Mediações vol. 20 n. 2 (Jul./Dez. 2015) - Londrina, 2015, p. 262-283.

LACLAU, Ernesto; MOUFFE, Chantal. Hegemonía y estratégia socialista: hacia uma radicalización de La democracia. Buenos Aires: Fondo de Cultura Econômica, 2006.

MACEDO, Renata Guedes Mourão. Trabalho doméstico, consumo e interseccionalidade: possibilidades de agência na trajetória de uma (ex)empregada doméstica. Mediações vol. 20 n. 2 (Jul./Dez. 2015) - Londrina, 2015, p. 184-207.

MARIANO, Silvana Aparecida. O sujeito do feminismo e o pós-estruturalismo. Revista Estudos Feministas, Florianópolis, v. 13, n. 3, p. 483-505, set./dez. 2005.

NUSSBAUM, Martha. Capabilities as fundamental entitlements: sen and social justice. Feminist Economics, London, v. 9, n. 2-3, p. 33-59, 2003.

NUSSBAUM, Martha. Las mujeres y el desarrollo humano: el enfoque de las capacidades. Barcelona: Herder Editorial, 2002.

SARDENBERG, Cecilia. Caleidoscópios de gênero: gênero e interseccionalidades na dinâmica das relações sociais. Mediações vol. 20 n. 2 (Jul./Dez. 2015) - Londrina, 2015, p. 56-96.

SÁ VILAS BOAS, Marie-Hélène. Deliberating on interseccionality: women's conferences in Recife. Mediações vol. 20 n. 2 (Jul./Dez. 2015) - Londrina, 2015, p. 208-234.

SEN, Amartya. Desigualdade reexaminada. 2. ed. Rio de Janeiro: Record, 2008.

SEN, Amartya. O desenvolvimento como expansão da capacidade. Lua Nova, São Paulo, n. 28-29, p. 313-334, 1993.

SEN, Amartya. Teorías del desarrollo a principio del siglo XXI. Mimeo, 2004. 